\title{
Proposição de Modelo Teórico de Pesquisa Identificador de Fatores Localizacionais Determinantes do Investimento Direto Estrangeiro
}

\author{
Gustavo Menoncin Pereira \\ gpereira@espm.br \\ EAESP - Fundação Getulio Vargas
}

\begin{abstract}
RESUMO
O interesse de investigar a decisão de empresas multinacionais que optaram pela Região Metropolitana de Campinas originou este trabalho. Para identificar os determinantes da localização industrial nesta região, dentro do contexto da nova geografia econômica, é proposto um modelo teórico de pesquisa. A construção do modelo conceitual tem como objetivo auxiliar o pesquisador a selecionar os construtos e as variáveis que serão incluídas no estudo. A proposta foi analisar as principais abordagens à questão localização, considerando as motivações e as vantagens que predispõem a empresa multinacional a investir no estrangeiro.Este artigo apresenta o desenvolvimento desta proposta. O modelo aqui apresentado foi desenvolvido para ser aplicado num estudo múltiplo de casos, com 14 empresas multinacionais da região. Os resultados da aplicação do modelo serão objeto de outro trabalho.
\end{abstract}

Palavras-chave: Localização. Fatores localizacionais. Empresas multinacionais. Investimento direto estrangeiro. Nova geografia econômica. 
O Brasil está, ano após ano, modernizando seu parque industrial. O investimento estrangeiro em novas instalações industriais multiplicou-se por quatro, desde 1994, sendo o país inserido dentro do contexto da Nova Geografia Econômica (NGE). As mais fronteiras às empresas multinacionais, ao decidirem buscar localidades para realizar seus investimentos, deixaram de existir.

A decisão de realizar o investimento direto estrangeiro em ativos como fábricas, envolve centenas de variáveis (mais de mil e setecentas, segundo o Conway Data, 2002) e valor econômico na ordem de bilhões de dólares para o país. Os fatores a serem avaliados constituem o problema a ser resolvido: onde localizar.

Esse tema tem interessado a cientistas dos mais diversos campos: Economia, Operações, Ciências Sociais e as Ciências Regionais têm produzido e estudos a respeito.

O assunto encontra em Dunning (1994) justificativas que motivam o investimento no estrangeiro pelas empresas multinacionais:

1. Acesso a fatores de baixo custo (low cost countries): mão-de-obra, materiais, capital, e componentes.O objetivo é maximizar a lucratividade sobre os custos de fabricação;

2. Acesso a recursos tecnológicos locais;

3. Proximidade a mercados, o que resulta em serviços melhores e mais rápidos.

Stern e Porter (2002) reforçam a importância da decisão da localização, para minimizar a competitividade global, as empresas devem aproveitar os pontos fortes de sua localização geográfica. No mesmo artigo, a questão dos clusters ou aglomeração das indústrias em determinada região é explorada. Determinadas regiões recebem investimentos de empresas do mesmo setor da indústria, criando parques tecnológicos e industriais.

No Brasil, a Região Metropolitana de Campinas, composta de 19 cidades, e 9\% do PIB brasileiro, concentra o segundo maior valor da produção industrial do país, superado apenas pelo da Região Metropolitana de São Paulo. Esta concentração de investimentos provocou o interesse de investigar o que determina a decisão da empresa multinacional a escolher a Região Metropolitana de Campinas para localizar seu investimento direto estrangeiro.

Este artigo propõe um modelo teórico de pesquisa para a realização deste estudo.

\section{METODOLOGIA}

O modelo teórico de pesquisa é desenvolvido através de extensa revisão da literatura (VOSS, 2002). A revisão deve assinalar a congruência e as contradições encontradas nos trabalhos que se relacionam diretamente ao assunto.

Echer (2001), citando Rudio (1999), sugere que o pesquisador faça a reelaboração da mensagem construindo novo texto com discussão e reflexão própria. A próxima etapa é, feita a revisão da literatura, imprimir os arquivos com as idéias afins e colocá-los sobre a mesa. Posteriormente, organizar as referências por inclusão. 
O trabalho de Gupta et all (2006) reforça o potencial de pesquisa que existe na interface entre Operações e outras áreas da administração e da economia. Pesquisa multidisciplinar é necessária, e tópicos tradicionais, como a questão da localização industrial, devem ser revistos dentro desta nova abordagem. Este tipo de estudo, que busca a interface de Operações com outras áreas, é sugerido para confirmar se as tradicionais visões ainda são válidas ou se precisam de ajustes.

No caso, as teorias foram associadas e interpretadas, seguindo a seqüência lógica do processo de revisão de literatura. O resultado foi proposição do modelo de pesquisa teórico que possa conduzir a pesquisa em busca da resposta à motivação, vantagens e fatores considerados para a empresa multinacional anunciar 0 investimento que irá realizar no estrangeiro.

\section{JUSTIFICATIVA}

Nas referências ao tema de localização, dificilmente são encontradas, na área de Operações, questões da nova geografia econômica. O foco de Operações é na quantificação dos fatores para a tomada da decisão, no ambiente de manufatura, com o objetivo de estimar o custo de produzir em determinada localidade.

Na nova geografia econômica, por sua vez, a decisão é discutida em torno do ambiente econômico. Grossa e Ryanb (2008) confirmam que tradicionalmente a decisão de realizar o investimento direto estrangeiro é motivada por aspectos mercadológicos ou pela disponibilidade de recursos em outro país. Mas os mesmos autores levantam a questão de que o custo de produzir pode influenciar a escolha da localização do investimento direto estrangeiro.

A principal justificativa para o desenvolvimento deste artigo é a lacuna causada pela não conexão dos dois pensamentos - falta de um modelo que busque entender o contexto econômico para depois avaliar os fatores de localização industrial.

O trabalho também se justifica pelo resgate da importância dos fatores que determinam a localização, e pelo entendimento do processo de internacionalização das empresas.

\section{OBJETIVO}

O objetivo principal do estudo é apresentar o modelo de pesquisa teórico que suporte os pesquisadores em suas investigações a cerca dos fatores que determinam o investimento direto estrangeiro.

Como objetivos específicos, identificar:

1) As fronteiras da nova geografia econômica e da teoria da localização;

2) As etapas do processo de decisão da localização;

3) Os fatores relevantes em cada etapa;

4) A intersecção da nova geografia econômica com a teoria da localização.

O Modelo teórico terá como papel na pesquisa guiar para que as questões a serem respondidas sejam repassadas sem esquecer pontos importantes. 


\section{MODELOS DE PROCESSOS PARA A DECISÃO DE LOCALIZAÇÃO}

Após revisar a literatura da área de Operações, é possível concentrar a evolução do tratamento da questão da localização em duas proposições: Carrol e Dean (1980) e Chopra e Meindl (2001). E complementar com os fatores que afetam a decisão de localização, segundo a proposta de Gaither and Frazier (2001).

Num estudo mais recente, González e Vazquéz (2007) classificam a localização como parte do conjunto de decisões estratégicas da manufatura que devem ser priorizadas. Neste estudo é abordado que a boa localização tem seu papel na construção da vantagem competitiva das empresas. Os aspectos sugeridos como influenciadores para tanto, são: proximidade a fontes de matérias primas, proximidade com o mercado, salários mais baixos, boa estrutura de transporte e de comunicações, disponibilidade de fornecedores e ambiente fiscal e legal favorável. Os trabalhos de Carrol e Dean (1980), Chopra e Meindl (2001), Gaither and Frazier (2001) exploram exaustivamente estes aspectos e a abordagem a ser dada.

O trabalho aqui apresentado evolui do modelo de Carrol e Dean, onde as decisões devem ser tomadas para determinar aspectos geográficos da localização. Os fatores (ou critérios) de localização e a importância relativa entre os mesmos são abordados por Gaither and Frazier. Chopra e Meindl incluem esta como parte integrante da estratégia da cadeia de suprimentos. E, voltando a Gaither e Frazier, a conexão da decisão com a nova geografia econômica é inicialmente tratada, pois a primeira decisão é a de que por qual país optar. Carrol e Dean iniciam pela escolha da região, conforme apresentado na Figura 1. 
Determinar:

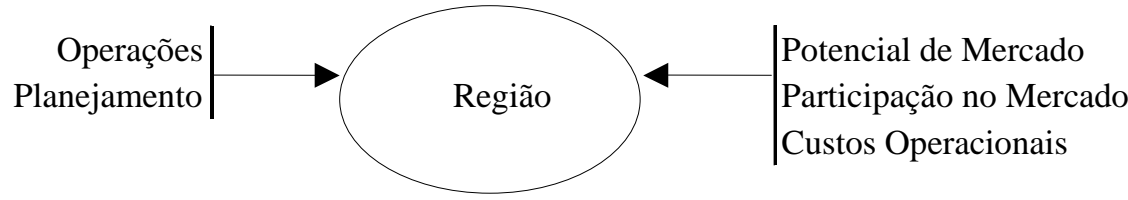

Determinar:

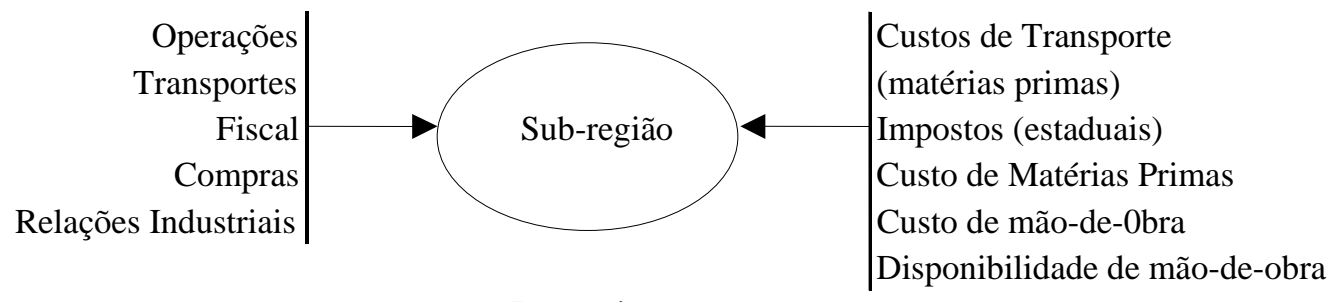

Determinar:
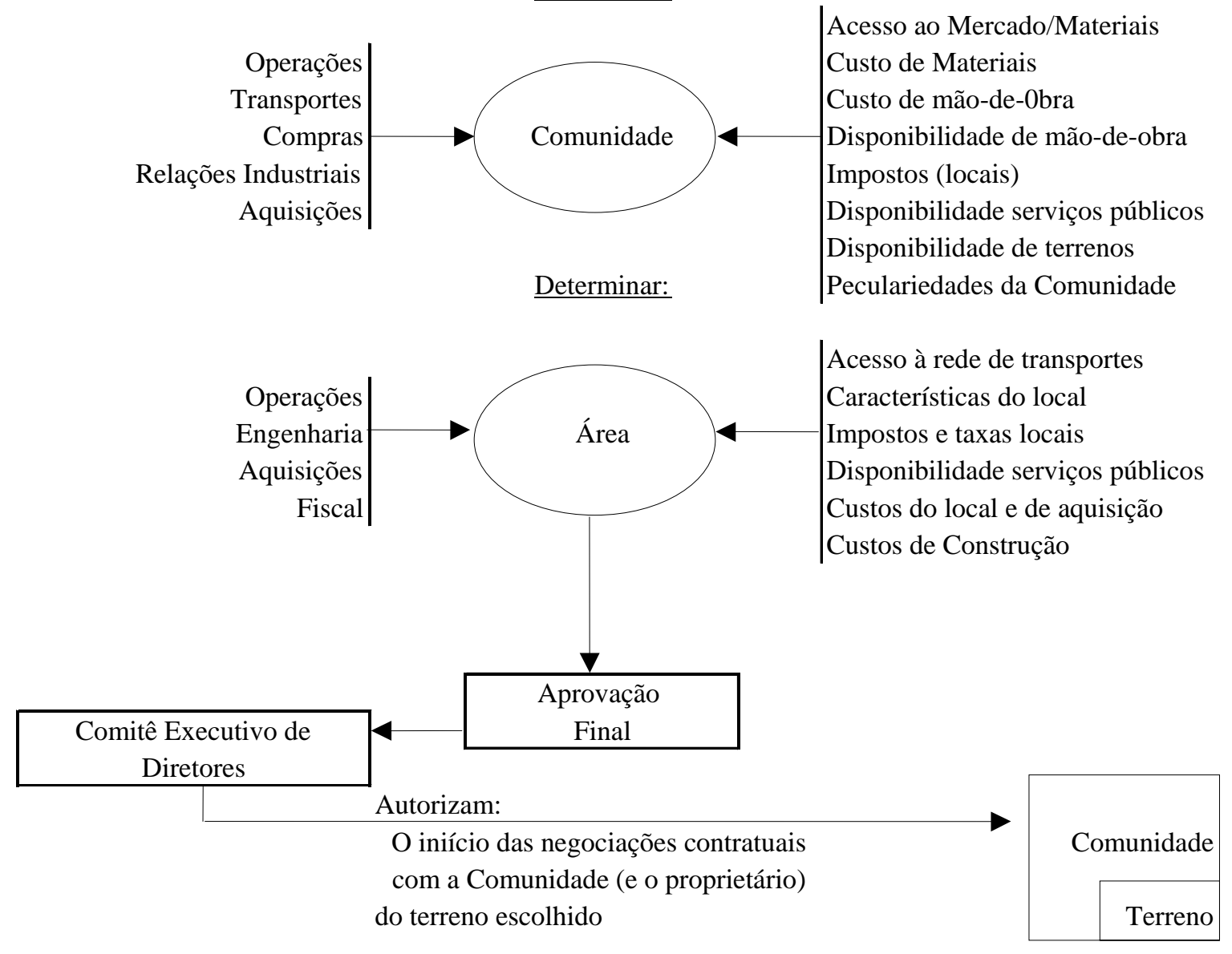

Fonte: Carrol e Dean $(1980 ; 87)$

Figura 1 - Proposta de Modelagem para a Decisão de Localização 
Gaither e Frazier (2001) salientam que as decisões quanto à localização de instalações não devem ser tomadas de maneira apressada. Estas decisões relativas à escolha de pontos estratégicos podem ser aflitivas e normalmente são resolvidas após longa e cuidadosa ponderação. No Quadro 1, os autores classificam os principais fatores e a importância relativa entre os mesmos, em diferentes instalações. A técnica dos autores é qualitativa (sistemas de estimativa de fatores), e fornece mecanismo para combinar diversos fatores em formato de fácil compreensão.

Quadro 1 - Importância Relativa dos Fatores de Localização em Diferentes Instalações

\begin{tabular}{|c|c|c|c|c|c|c|c|c|}
\hline $\begin{array}{l}\text { Fator que afeta a } \\
\text { decisão quanto à } \\
\text { Localização }\end{array}$ & $\begin{array}{l}\text { Mineração, } \\
\text { Lavra, } \\
\text { Manufatura } \\
\text { Pesada } \\
\end{array}$ & $\begin{array}{l}\text { Manufatura } \\
\text { Leve }\end{array}$ & $\begin{array}{c}\text { P\&D e } \\
\text { Manufatura } \\
\text { High-Tech }\end{array}$ & $\begin{array}{l}\text { Armaze- } \\
\text { namento }\end{array}$ & $\begin{array}{l}\text { Venda e } \\
\text { Varejo }\end{array}$ & $\begin{array}{l}\text { Serviços ao } \\
\text { Clientes } \\
\text { com Fins } \\
\text { Lucrativos } \\
\end{array}$ & $\begin{array}{l}\text { Serviços do } \\
\text { Governo } \\
\text { Municipal }\end{array}$ & $\begin{array}{l}\text { Serviços de } \\
\text { Saúde e } \\
\text { Emergência }\end{array}$ \\
\hline $\begin{array}{l}1 \text { Proximidade de } \\
\text { concentrações } \\
\text { de clientes e } \\
\text { cidadãos } \\
\end{array}$ & C & C & B & A & A & A & A & A \\
\hline $\begin{array}{l}2 \text { Disponibilidade } \\
\text { e custos de mão- } \\
\text { de-obra }\end{array}$ & B & A & B & B & B & A & B & B \\
\hline $\begin{array}{l}3 \text { Atratividade da } \\
\text { comunidade } \\
\text { para recrutar } \\
\text { profissionais } \\
\end{array}$ & C & B & A & $\mathrm{C}$ & $\mathrm{C}$ & $\mathrm{C}$ & C & $\mathrm{C}$ \\
\hline $\begin{array}{l}4 \text { Grau de } \\
\text { Organização } \\
\text { sindical } \\
\end{array}$ & A & A & C & B & B & B & C & B \\
\hline $\begin{array}{l}5 \text { Custos de } \\
\text { construção e } \\
\text { terrenos } \\
\end{array}$ & A & B & B & B & B & B & B & B \\
\hline $\begin{array}{l}6 \text { Proximidade de } \\
\text { instalações de } \\
\text { transporte } \\
\end{array}$ & A & B & C & A & B & C & C & $\mathrm{C}$ \\
\hline $\begin{array}{l}7 \text { Custos de } \\
\text { transporte das } \\
\text { entradas }\end{array}$ & A & B & C & A & B & C & C & C \\
\hline $\begin{array}{l}8 \text { Custos de } \\
\text { transporte das } \\
\text { saídas }\end{array}$ & B & B & C & A & $\mathrm{C}$ & C & C & $\mathrm{C}$ \\
\hline $\begin{array}{l}9 \text { Disponibilidade } \\
\text { e custos de } \\
\text { serviços } \\
\text { públicos } \\
\end{array}$ & A & B & C & $\mathrm{C}$ & $\mathrm{C}$ & $\mathrm{C}$ & $\mathrm{C}$ & $\mathrm{C}$ \\
\hline $\begin{array}{c}10 \text { Proximidade de } \\
\text { matérias primas } \\
\text { e suprimentos }\end{array}$ & A & B & C & $\mathrm{C}$ & C & C & C & C \\
\hline $\begin{array}{l}11 \text { Restrições de } \\
\text { zoneamento e } \\
\text { impacto } \\
\text { ambiental }\end{array}$ & A & B & C & $\mathrm{C}$ & C & B & C & C \\
\hline
\end{tabular}

Legenda: A: Muito Importante; B: Importante; C: Menos Importante Fonte: Gaither e Frazier (2001:183) 
Chopra e Meindl (2001) propõem que a tomada de decisão de localizar a nova instalação é dividida em quatro etapas:

1) Definição da Estratégica da Cadeia de Suprimentos

2) Configuração da Região

3) Alternativas de Localização

4) Escolha da Localização.

A figura 2 apresenta este modelo e suas fases. A proposta dos autores é de amplitude estratégica e alinhada ao Supply Chain Management, e às tradicionais abordagens da área de Operações. Chopra e Meindl incorporam a competição global como a ser considerada na definição da estratégia de suprimentos (Fase I).

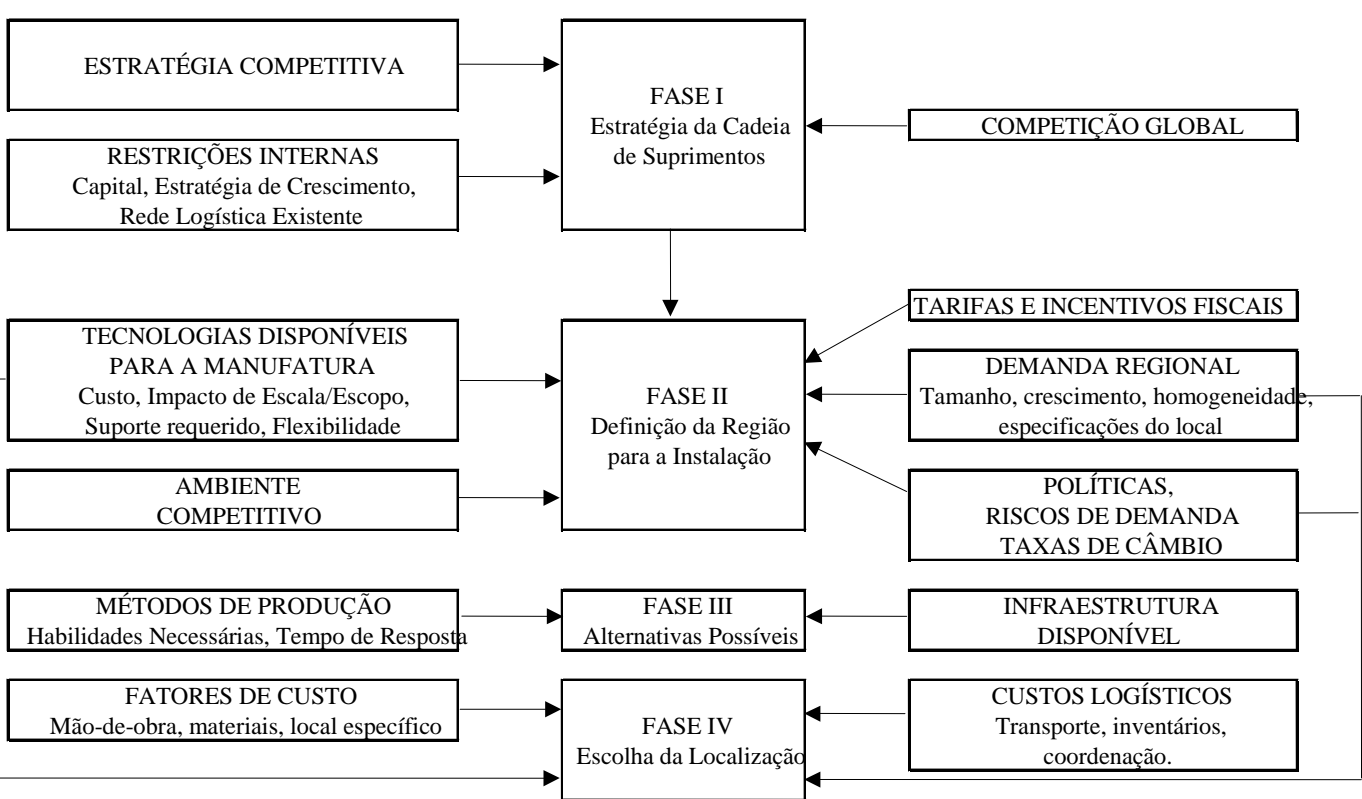

Fonte: Chopra e Meindl (2001:314)

Figura 2 - Proposta de Modelagem para a Decisão de Localização

Gaither and Frazier (2001) apresentam a seqüência de decisões quanto à localização, agrupando os fatores que afetam as mesmas:

1. Decisão Nacional: estabilidade do Governo, Economia e Sistema Político; disponibilidade e Custos de mão-de-obra; cotas de exportação e importação. Taxas alfandegárias e comissões; taxas de câmbio da moeda; sistemas de transporte; oferta de energia; sistema de telecomunicações; disponibilidade de custos e materiais de suprimentos; clima; incentivos e restrições governamentais; peculiaridades culturais e econômicas; regulamentação quanto às operações;

2. Decisão Regional: concentração e tendências de clientes e cidadãos; disponibilidade e custos de mão-de-obra; grau de organização sindical; custos de construção e de terras; oferta e custos de serviços públicos; 
disponibilidade de sistemas de transportes; custos dos transportes; disponibilidade e custos de materiais e suprimentos; clima; incentivos governamentais. Regulamentação ambiental;

3. Decisão Comunitária: conscientizações e tendências de clientes e cidadãos; preferência da administração; serviços comunitários e impostos; atitudes comunitárias em relação às localizações; disponibilidade e custos de mão-deobra; disponibilidade e custos de locais; custos de construção; disponibilidade de sistemas de transporte; custos dos transportes; disponibilidade e custos de materiais e suprimentos; serviços bancários; regulamentação e impactos ambientais; incentivos governamentais;

4. Decisão quanto ao local: concentrações e tendências de clientes e cidadãos; custos e locais; tamanho dos locais; proximidade a Sistemas de Transportes; disponibilidade de Serviços Públicos; restrições de zoneamento; proximidade a indústrias de serviços relacionadas; impacto ambiental; disponibilidade e custos de materiais e suprimentos.

\section{ECONOMIA DA EMPRESA MULTINACIONAL}

\subsection{O Paradigma Eclético de Dunning}

Demirbag et all (2007) descreve o Paradigma Eclético de Dunning como uma abordagem holística para explicar o nível de atividade e os padrões da produção internacional. Segundo os autores, Dunning simplesmente combina vários fatores que oferecem grande explicação das atividades das multinacionais e seus investimentos no estrangeiro, que nenhuma outra abordagem proporciona. Este paradigma visa explicar a produção no estrangeiro (DUNNING, 1977;1979) e se baseia em três abordagens teóricas:

a) Economia industrial - procura explicar como é possível que determinadas empresas adquiram e sustentem uma ou várias vantagens competitivas em relação às outras;

b) Teoria da empresa, que busca explicar o modo que a empresa está organizada para criar, aumentar e usar estas vantagens;

c) Teoria da localização, que explica onde as empresas escolhem localizar suas atividades.

\subsection{As Vantagens de Investir no Estrangeiro}

As vantagens específicas (Economia Industrial) de propriedade podem ser de dois tipos: vantagens estruturais, relacionadas aos ativos possuídos com exclusividade pela empresa em relação aos demais concorrentes (como tecnologia superior ou processo de produção eficiente); e vantagens de transação, 
relacionadas aos benefícios obtidos pela empresa a partir da gestão comum de um conjunto de atividades relacionadas, no país e no exterior. Pode-se, também, adquirir vantagem específica de propriedade a partir de alianças com outras empresas (DUNNING, 1995).

As vantagens de internalização (Teoria da empresa) remetem à capacidade da empresa em transferir suas vantagens específicas de propriedade de modo interno à sua própria estrutura. Isso se dá na medida em que ela percebe ser de seu melhor interesse internalizar o mercado para essas vantagens do que cooperar com outras firmas para explorá-las. Essa percepção é determinada pelos custos de coordenação e transação das modalidades alternativas.

As vantagens de localização (Teoria da localização) são oriundas da utilização combinada dos fatores de produção disponíveis em outros países. Elas podem ser estruturais, quando relativas às diferenças nos custos dos fatores de um país para outro. Quando associadas ao aproveitamento de oportunidades no mercado e à redução de riscos sob condições de contrato com fornecedores e clientes, são chamadas de transacionais. Ambientes onde se encontram aglomerados muitos recursos complementares podem criar benefícios adicionais devido a sua proximidade (DUNNING, 1995).

\subsection{A Motivação para Investir no Estrangeiro}

Outro aspecto importante é a motivação que faz com que a empresa Multinacional realize o Investimento Direto Estrangeiro (IDE). Segundo Dunning (1994), os motivos podem ser classificados em: resource seeking, market seeking, efficiency seeking e strategic asset seeking.

Resource seeking e market seeking se referem à motivação para o primeiro investimento em país estrangeiro:

Resource seeking são os investimentos orientados para a exploração de mãode-obra não qualificada, ou recursos naturais, sendo que a disponibilidade é a principal vantagem da localização oferecida pelo país candidato a receber o IDE.

Market seeking, a referência é feita para explorar o mercado doméstico do país candidato e de seus vizinhos.

Após o investimento inicial, em razão do desenvolvimento econômico, ou da liberalização comercial ou da concorrência, os investimentos de market seeking dão lugar aos de efficiency seeking. Estes buscam racionalizar a produção para explorar economias de especialização e localização.

Já o strategic asset seeking, tem como estratégia adquirir recursos e competências que podem ajudar a empresa investidora a manter e aumentar suas competências competitivas nos mercados regionais ou globais (DUNNING 1994).

\section{A NOVA GEOGRAFIA ECONÔMICA}

Weber (1929) faz distinção entre concentração industrial e aglomeração industrial. Por concentração entende-se qualquer reunião de unidades produtivas na mesma localização, independentemente da causa desta reunião. Aglomeração é a reunião de unidades produtivas devido a economias de escala internas ou externas. Surge quando a reunião de unidades produtivas, servindo diversos mercados e 
situados em diferentes posições, se fizer para aproveitar as vantagens das economias de escala.

Segundo Suzigan (2000), aglomeração industrial pode se basear na:

i. Experiência dos distritos industriais italianos ou europeus de modo geral;

ii. Natureza localizada da inovação tecnológica na dinâmica industrial;

iii. Economia regional para estabelecer relação entre geografia econômica e desempenho industrial;

iv. Estratégia da empresa na busca por vantagens competitivas geograficamente restritas;

v. Nova Geografia Econômica (NGE).

A mudança nos fluxos de negócios desenha a geografia das atividades das multinacionais e do Investimento Direto Estrangeiro. Basta observar que a distribuição da atividade econômica não é uniforme. Em 2000, 50\% de todo o produto mundial foi produzido por $15 \%$ da população mundial (HENDERSON, 2000) e $54 \%$ por países que ocupavam apenas $10 \%$ da área do mundo. A metade mais pobre da população mundial produziu 14\% do produto mundial e 17 das 20 mais pobres nações estavam no continente africano.

No contexto internacional, de acordo com Puga (1999), a demanda mundial por produtos manufaturados amplia as diferenças de ganhos entre os países que têm as indústrias e aqueles que não as têm. Alternativas de fabricar num país industrializado versus a oportunidade de se produzir em outro com ganhos mais altos são consideradas. As fábricas começam a se mover de centros tradicionais para regiões de baixo custo. Com isto, os potenciais países receptores buscam estabelecer políticas públicas orientadas a consolidar aglomerações industriais como pólos geradores de crescimento, emprego, renda, desenvolvimento tecnológico e exportações.

Krugman (1991) denominou a Nova Geografia Econômica (NGE) como a "quarta onda" (após a organização industrial, o comércio internacional e a teoria de crescimento). Segundo o autor, a NGE estuda a aglomeração espacial da atividade econômica, provendo fundamentação microeconômica para a análise de como este fenômeno afeta a estrutura da indústria e comércio.

A reestruturação geográfica dos fluxos de comércio mundial de manufaturados provocada pela perda de competitividade de plantas sediadas na Europa e no Japão é comentada por Frisch e Franco (1991): "influência dominante na determinação dos fluxos de investimento para fora das economias centrais".

Algumas das razões citadas para que as firmas busquem atravessar fronteiras geográficas são:

1) O IDE é a alternativa natural para empresas que possuem vantagens competitivas específicas não transferíveis entre indústrias;

2) A mobilidade intersetorial de recursos, pela rigidez;

3) A diversificação de plantas produtoras de bens comercializáveis entre as diferentes áreas monetárias tornou-se um comportamento racional, pois se confirmou a expectativa generalizada sobre a permanência da volatilidade cambial. 
Segundo os autores existe um elo de ligação entre: mudanças nos padrões de comércio em empresas de manufatura, distribuição da origem geográfica e setorial do IDE e oportunidades de comércio para a periferia semi-industrializada.

Monastério (2008) descreve o racional da NGE como a forma das nações ricas manterem sua posição, com as empresas multinacionais buscando economias de escala através da aglomeração, urbanização e proximidade com mercados existentes. O objetivo da NGE para as corporações é de localizar suas instalações em áreas que tenham como ideal novos clientes, aumentando seus negócios e vantagens competitivas, e mantendo a concentração de receitas geradas.

\section{PROPOSTA DE UM MODELO TEÓRICO DE PESQUISA}

Stafford (1980) define o processo de tomada de decisão de localização como uma arte, sendo ciência inexata. Classifica a natureza da decisão de localização como expandir o local onde já vem operando ou investir em nova instalação em novo local. Krumme (1969) define processos que envolvem decisões espaciais nas empresas. Estes processos, segundo Krumme, podem se originar por uma prática passiva, decidida por políticas de acessar mercados, ou ativa, orientadas pelo planejamento da produção. Em ambos os casos as empresas podem sobreviver ou não.

A proposta deste modelo é abordar os fatores econômicos e os da teoria de localização conjuntamente. Pretende ressaltar como é importante para o sucesso e sobrevivência da empresa a consideração de fatores econômicos e de produção para a condução do processo. A empresa que decide pela localização sem critérios, análises e estudos pré-estabelecidos, tem suas chances de sucesso dependentes de subsídios governamentais ou estruturas de mercado - ou até mesmo por acidente ou sorte.

Existe, segundo Stafford (1980), considerável literatura na qual os pesquisadores reportam as respostas dos investidores para as questões do porquê suas instalações estão nos locais onde estão. Muito do que sabemos sobre a importância relativa dos vários fatores localizacionais vêm destes estudos, que apresentam dois elementos comuns:

1) Ocorrem após o fato ter acontecido (after the fact), e nestes casos o tempo é consciente ou subconsciente razão para racionalizar ou justificar a localização escolhida;

2) São estruturados, sempre a priori, ao redor das variáveis econômicas básicas, assim descritas pela teoria econômica, e, desde que os tomadores de decisão trabalham sobre a pressão de produzir resultados economicamente racionais, os mais óbvios, mas talvez mais importantes processos de decisão, não são adequadamente explorados.

Rees e Stafford (1986) sugerem que as entrevistas para os levantamentos a cerca destes estudos devem ser feitas in loco, dispensando questionários escritos. Os resultados são muito mais próximos da realidade e se conformam à teoria de 
localização. A seguir são listados princípios sob os quais os tomadores de decisão de localização se orientam, baseada no trabalho dos autores:

a) O problema de localização não é preocupação comum; na maioria das vezes o mesmo é explicitado quando está claro que capacidade produtiva adicional é necessária;

b) A maioria das decisões de localização de novas plantas é em resposta à necessidade de capacidade adicional;

c) A velocidade que a empresa responde pela demanda de capacidade varia de acordo com a qualidade, escopo e natureza das diretrizes de crescimento da empresa - organizações acostumadas a se expandir tendem a desenvolver planos específicos de crescimento e a se mover mais rapidamente, do que as empresas com taxas de crescimento mais modestas;

d) Os tomadores de decisão transformam a infinita complexidade do problema de localização ótima em algo simples. Através de mapas, o espaço regional a ser considerado é simplificado, reduzindo as alternativas.

e) Os tomadores de decisão também simplificam e controlam seu ambiente não explorando análises complexas quando os ganhos não estão claros ou sem garantia. Na verdade, eles tentam evitar, quando possível, a implementação de qualquer solução a qual pode ser difícil e complexa de ser negociada com grupos ou agências governamentais;

f) A decisão final é feita ou ratificada pelos mais altos escalões de executivos das empresas. As decisões de localização são vistas como de longo prazo, mas tomadas com informações e projeções relativamente de curto prazo;

g) O processo de decisão é visto como lógico e racional.

Os processos de decisão tendem a se conformar a modelos gerais e possuem denominadores comuns fortes entre eles, segundo Stafford (1980):

1) Identificação da necessidade: novas instalações são construídas para atender expansão da demanda, modernizar fábricas e instalações ou para escapar de situações desfavoráveis quanto à mão-de-obra. A natureza das necessidades da corporação influencia o processo de busca espacial;

2) Pré-condições operacionais: a vasta gama de possibilidades de alternativas nunca é explicitamente explorada no processo de procura. Muitas são excluídas por decisões subjetivas. (preferir o local onde a empresa sempre esteve; avaliar as alternativas individualmente, não simultaneamente).

A congruência e as contradições encontradas nos trabalhos que se relacionam diretamente ao assunto tema deste artigo fundamentam a construção do modelo teórico de pesquisa. A finalidade é auxiliar o pesquisador a selecionar os construtos e as variáveis que serão incluídas no estudo. 
Este modelo tem como proposta:

Contextualizar:

Definir as etapas: o processo de decisão de localização dentro da Nova Geografia Econômica. (DUNNING, 1999; KRUGMAN, 1991; SUZIGAN, 2000; STERN E PORTER, 2002; PUGA, 1999).

do processo de tomada de decisão de localização. (CHOPRA e MEINDL, 2001; CARROL e DEAN, 1980; GAITHER E FRAZIER, 2001).

A premissa do modelo teórico de pesquisa é que existe uma seqüência no processo de decisão de investimento direto estrangeiro. Esta seqüência é suportada em cada etapa pela análise de fatores e considera aspectos macro e micro da Economia.

A lógica desta proposição se inicia pela motivação para investimento direto estrangeiro, que pode ser gerada para explorar novo país, ou aumentar capacidade produtiva em local estrangeiro onde já existe presença. Esta consideração e mais a busca por vantagens para obter o sucesso internacional criam o ambiente teorizado pela Nova Geografia Econômica.

Este ambiente faz com que as multinacionais a expandir suas fronteiras para outros países onde o parque tecnológico e produtivo não possui capacidade local. A partir da decisão nacional, o país escolhido a ser estudado, deve passar pelas etapas do processo de decisão, onde os fatores de localização relacionados às estas etapas serão avaliados.

Estes fatores ao serem analisados, irão gerar a base de dados e informações que determinarão regiões e cidades como candidatas a receberem o investimento direto estrangeiro.

O modelo teórico de pesquisa, apresentado na Figura 3, é um instrumento que tem como principal utilidade investigar e classificar:

a) As vantagens identificadas pela empresa multinacional em investir no país e mais especificamente na região.

b) A motivação para o Investimento Direto Estrangeiro.

c) A inserção do país como ambiente para a Nova Geografia Econômica.

d) As etapas do processo de decisão de localização das instalações.

e) Os fatores considerados e a relatividade entre os mesmos. 


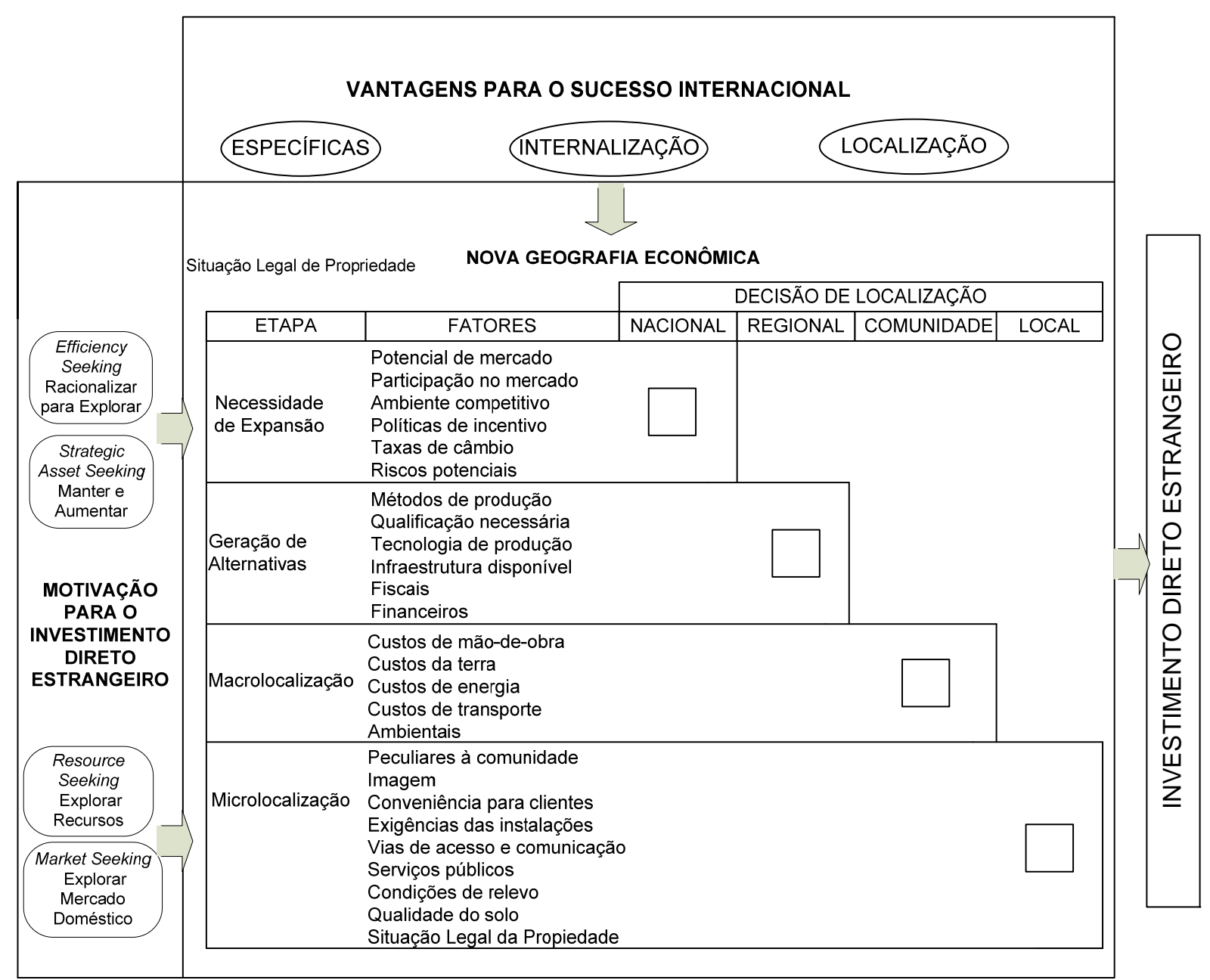

Figura 3 - Proposta de Modelo Teórico de Pesquisa

Este modelo, desenvolvido nas bases teóricas apresentadas, será testado no processo de pesquisa junto às empresas que decidiram direcionar seus investimentos em novas instalações na Região Metropolitana de Campinas.

Resultados da aplicação do modelo na pesquisa em questão serão divulgados quando da proposição de novo artigo para publicação no meio científico, assim que os dados forem consolidados. As expectativas desta pesquisa é que as seguintes hipóteses sejam testadas:

1) A região metropolitana de Campinas é atrativa por possuir fatores de localização que superam os incentivos e benefícios fiscais de outras regiões;

2) As decisões de localização na região foram motivadas dentro do contexto da nova geografia econômica;

3) Os fatores de localização industrial tradicionais são considerados no processo de tomada de decisão.

4) As vantagens e a motivação do Paradigma Eclético de Dunning são avaliadas para a tomada de decisão. 


\section{CONCLUSÕES}

Este trabalho tem como objetivo contribuir com os estudos que envolvem o processo de tomada de decisão de multinacionais na escolha do destino de seu investimento. Para atingir este objetivo, apresenta o modelo teórico construído a partir da revisão da literatura. Como o pressuposto é que as questões de Economia e da Teoria da Localização estão cada vez mais associadas, o trabalho buscou referências de ambos os campos.

Complementa o estudo a questão da Nova Geografia Econômica. As possibilidades da tomada de decisão dentro deste contexto dão relevância ao assunto, como decisão de investir no estrangeiro.Mas o detalhamento do local a ser escolhido ainda tem nos modelos tradicionais as técnicas de avaliação mais adequadas.

Durante a revisão da literatura, a principal conclusão é que os modelos que orientam os processos de tomada de decisão de localização são focados em auxiliar na avaliação da escolha geográfica. Os motivos e os porquês da escolha do país em questão não estão contemplados nestas proposições. Do ponto de vista da Economia, os avanços e o interesse pelo assunto progrediram de forma proporcional à abertura comercial que os países e as regiões proporcionaram entre si. Isso, somado a teorias econômicas que expandiram os horizontes e a importância do tema, como a já citada nova geografia econômica.

O trabalho busca apresentar um modelo que conecte as ciências econômicas e aquelas estudadas principalmente pela área de Operações. Propõe aos administradores das empresas a visão sistêmica do processo de decisão da localização do investimento direto estrangeiro. A recomendação é, na pesquisa, não apenas se concentrar na localização geográfica, e tão pouco apenas estudar os fluxos de capital estrangeiro para o país. A proposta é entender que fatores localizacionais de uma região atraem dinheiro estrangeiro para aquela cidade, estado e país.

$\mathrm{Na}$ atual conjuntura econômica mundial (Nova Geografia Econômica), decidir a localização de entidade produtiva de empresa multinacional não se limita mais a fronteiras.

As oportunidades podem ser exploradas em todas as alternativas mundiais possíveis. Isto impulsiona o investimento direto estrangeiro no sentido de otimizar recursos e manter a posição econômica dos países de onde as empresas multinacionais se originaram.

Como última consideração, a funcionalidade deste modelo só poderá se comprovar na própria pesquisa que o originou. São 14 empresas multinacionais da região metropolitana de Campinas que investiram em instalações nesta localidade. A partir desta experiência, e com os resultados obtidos, poderá ser constatada o quanto esta proposta contribui na condução de pesquisas desta natureza.

\section{ABSTRACT}

In order to investigate the reasons why multinational companies choose Campinas Metropolitan Area, this paper was originated. A theoric research model, that deals with the determinants of the industrial location in this region, within the context of the new economic geography, is proposed. The construction of a conceptual framework 
will help the researcher to select the constructs and the variables to be included in the study. The proposal is to cover the main approaches to the location issues taking into consideration what motivation and advantages a multinational company may have to make foreign investments. This paper presents the development of this proposal. The presented model was developed for conducting a multiple case study, with 14 multinational companies in the region. The results of its application will be discussed in another paper.

Keywords: localization; localizational factors; multinational companies; foreign direct investment; new economic geography

\section{REFERÊNCIAS}

CARROL, Thomas M.; DEAN, Robert D. A Bayesian Approach to Plant-Location. Decisions Decision Sciences, v. 1, n. 1. p. 81-89, January, 1980.

CHOPRA, Sumil; MEINDL, Peter. Supply Chain Management: strategy, planning, and operation. New Jersey: Prentice Hall, 2001.

CONWAY, Data. The Strategy Alignment Model: Defining Real Estate Strategies. The Context of Organizational Outcomes Site Selection Magazine, Norcross, GA, USA, p. 46-48, January 2002.

DUNNING, John $\mathrm{H}$. Trade, location of economic activity and the multinational enterprise: a search for an eclectic approach. In: OHLIN, B.; HESSELBRON, Per Ove; WIJKMAN, Per Magnus (Ed.). The international allocation of economic activity. London: Macmillan, 1977. (Reimpresso In: DUNNING, John. International production and the multinational enterprise. London: George Allen \& Unwin, 1981, p. 46-71).

Explaining Changing Patterns of International Production: Defence of the Eclectic Theory Oxford Bulletin of Economics and Statistics, v. 41, n. 4, p. 269295, 1979

Re-evaluating the Benefits of Foreign Direct Investment Transnational Corporations Journal, v. 3, n. 1, p. 23-51, 1994.

. Reappraising the Eclectic Paradigm in an Age of Alliance Capitalism. Journal of International Business Studies, 3. quarter, p. 461-493, 1995.

. Globalization and the Theory of MNE Activity Discussion Papers in International Investment and Management, n. 264, January, 1999.

ECHER, Isabel C. Revisão de Literatura na Construção do Trabalho Científico. Revista Gaúcha de Enfermagem, Porto Alegre, v. 22, n. 2, p. 5-20, jul. 2001.

FRISCH, Winston, FRANCO, Gustavo. O Investimento Estrangeiro em uma Nova Estratégia Industrial: o Brasil e a nova economia mundial. Rio de Janeiro: José Olympio Editora, 1991. 
GAITHER, Norman FRAZIER, Greg. Administração da produção e operações. 8. ed. São Paulo: Pioneira Thomson Learning, 2001.

URGAL-GONZALÉZ, Begõna ; GARCIA-VÁZQUEZ, Jose Manuel The Strategic Influence of Structural Manufacturing Decisions International. Journal of Operations \& Product Management, v. 27, n. 6, p. 605-626, 2007.

GROSSA, Dominique M.; RYANB, Michael J. FDI location and size: Does employment protection legislation matter? Regional Science and Urban Economics, 6. edition, v. 38, p. 590-605, nov., 2008.

GUPTA, Sushil; VERMA, Rohit; VITORINO, Liana. Empirical Research Published in Production and Operations Management (1992-2005): trends and Future Research Directions. Production and Operations Management, London, v. 15, n. 3, 2006.

KRUGMAN, P. Geography and Trade. Cambridge: MIT Press, 1991.

What's new about the new economic geography? Oxford Review of Economic Policy, v. 14, n. 2, p. 7-17, summer, 1998.

KRUMME, Gunter Toward. A Geography of Enterprise. Economic Geography, v. 45, n. 1, p. 30-40, January, 1969.

MONASTÉRIO, Leonardo M. Brazilian Spatial Dynamics in the Long Term (18722000): "Path Dependency" or "Reversal of Fortune"? In: CONFERENCE OF THE REGIONAL SCIENCE OF THE AMERICAS, Cartagena de Indias, 2009.

Proceedings . . . Cartagena de Indias, 2009. Paper n. 2242.

PUGA, D.; VENABLES, A J. Agglomeration and Economic Development: import substitution versus trade liberalization. Economic Journal, St. Andrews, United Kingdom. n.109, p. 292-311, 1999.

REES, J.; STAFFORD H. Theories of Regional Growth and Industrial Location: Their Relevance for Understanding High-Technology Complexes. In: REES J., Technology, Regions, and Policy. Edited by John Rees. Totowa, New Jersey: Rowman \& Littlefield, Chapter 2, 1986.

STAFFORD, Howard. A Principles of Industrial Facility Location. Norcross, GA, USA. Conway Publications Inc, 1980

STERN, Scott e PORTER, Michael. Inovação e Localização de Mãos Dadas. HSM Management, São Paulo, n. 30, ano 5, 2002

SUZIGAN, Wilson. Aglomerações Industriais como Foco de Políticas. Revista de Economia Política, v. 21, n. 3, jul./ set. 2001

VOSS, Chris; TSIKRIKTSIS, Nikos; FROHLICH, Mart. Case research in operations management International. Journal of Operations \& Production Management, v. 22, n. 2, 2002. 
WEBER, Alfred. Theory of the Location of Industries. Chicago: The University of Chicago Press, 1929. Traduzido por Carl J. Friedrich a partir do livro de 1909 